\title{
Evaluation of a chicory root cold store humidification system using computational fluid dynamics
}

\author{
M.A. Delele ${ }^{\mathrm{a}, *}$, A. Schenk ${ }^{\mathrm{b}}$, H. Ramon ${ }^{\mathrm{a}}$, B.M. Nicolaï ${ }^{\mathrm{a}, \mathrm{b}}$, P. Verboven ${ }^{\mathrm{a}}$ \\ a BIOSYST-MeBioS, Katholieke Universiteit Leuven, Willem de Croylaan 42, 3001 Leuven, Belgium \\ ${ }^{\mathrm{b}}$ Flanders Centre of Postharvest Technology, Willem de Croylaan 42, 3001 Leuven, Belgium
}

\section{A R T I C L E I N F O}

\section{Article history:}

Received 9 December 2008

Received in revised form 2 March 2009

Accepted 3 March 2009

Available online 11 March 2009

\section{Keywords:}

CFD

Cold storage

Humidification

Lagrangian model

Multiphase flow

Porous media

Chicory root

\begin{abstract}
A B S T R A C T
Humidification of chicory root cold stores helps in maintaining the quality and extending the postharvest storage time of chicory roots. Low evaporation rate of the sprayed droplets at such sub-zero temperatures $\left(-2{ }^{\circ} \mathrm{C}\right.$ to $\left.-1{ }^{\circ} \mathrm{C}\right)$ favours surface deposition that could have an adverse effect on the efficiency of the storage room. A three-dimensional computational fluid dynamics (CFD) model was developed and used to predict the storage room air velocity, temperature and humidity distributions, and fate of the water droplets that were sprayed for humidifying the storage room. The humidification system in a chicory root cold store was then optimized. The efficiency of the humidification system was affected by length of cold air deflector, stack height, number of nozzles and duration of humidification. Elongating the air deflector, reducing the stack height, reducing the number of nozzles and shortening the humidification time increased the amount of droplet evaporated and decreased the amount of droplet deposited on the stack. The following combinations of room design and operating parameters could clearly give the best performance of the humidification system: deflector length of $0.8 \mathrm{~m}$, two nozzles with an interval humidification of 1.5 min on and 2 min off cycle and stack height of $3.4 \mathrm{~m}$.
\end{abstract}

(c) 2009 Elsevier Ltd. All rights reserved.

\section{Introduction}

Fruit and vegetable products are highly perishable that continue to respire and transpire water after harvest. For long term storage of these products, cold storage systems are commonly used. The cooling is usually performed by forcing cold air through the stored product. A low optimum storage temperature combined with a high relative humidity $(\mathrm{RH})$ of the surrounding air can reduce the product moisture loss. Water loss during postharvest storage of fruits and vegetable products has an adverse effect on product quality and economic return (Henriod, 2006; Hertog et al., 2004; Paull, 1999; Sujau et al., 2005; Tu et al., 2000). However, an excessive $\mathrm{RH}$ level may encourage the development of moulds and rots and deposition of water droplet on products and room surfaces (Sujau et al., 2005; Tassou and Xiang, 1998).

Chicory roots are very susceptible to dehydration; this dehydration leads to lower yield and quality, higher percentage nonsprouting roots and longer forcing period (De Proft et al., 2000; Embrechts, 1989). For long storage (for about 9 months), chicory roots are usually stored at $-2{ }^{\circ} \mathrm{C}$ to $-1{ }^{\circ} \mathrm{C}$ with a $\mathrm{RH}$ of $95-100 \%$ (Hoang et al., 2003; Neefs et al., 2000; Seynnaeve et al., 2000). In order to achieve the required $\mathrm{RH}$ (minimum of 95\%), humidifiers are usually installed.

\footnotetext{
* Corresponding author. Tel.: +32 16322376; fax: +32 16322955.

E-mail address: mulugetaadmasu.delele@biw.kuleuven.be (M.A. Delele).
}

The requirements for the humidification system are to produce a high RH with maximum droplet evaporation, minimum deposition of sprayed water droplet on the product and room surfaces, and minimum frost/condensation on the air cooling coils. However, fulfilling these requirements is very challenging; Fig. 1 shows the problem of ice accumulation over a stack of boxes with chicory roots. This accumulated ice can affect the cooling efficiency of the room by blocking the circulation of the cooling air. Such adverse effects can be minimized by optimizing the design and operation of the humidification system.

A number of previous studies demonstrated the applicability of CFD models for analyzing the flow inside and around cold storage systems (Chourasia and Goswami, 2007; Foster et al., 2002; Hoang et al., 2000, 2003, 2004; Nahor et al., 2005; Tassou and Xiang, 1998; Xu and Burfoot, 1999). None of these studies had modelled the humidification system. Recently, we developed a validated model that can predict the storage room air velocity, temperature and humidity distributions and fate of the water droplets that were sprayed from humidifying nozzles (Delele et al., 2009).

The aim of this paper is to apply the validated model of Delele et al. (2009) to evaluate a chicory root cold store humidification system. The study was used to analyse the effects of different cold store designs and humidification system operating parameters, and to recommend solutions that could improve the efficiency of the cold store and the humidification system. However, the recommendations were not based on a detailed optimization study of the 


\begin{tabular}{|c|c|c|c|}
\hline \multicolumn{4}{|c|}{ Nomenclature } \\
\hline$C_{d}$ & drag coefficient & $T$ & temperature, $\mathrm{K}$ \\
\hline$C_{p}$ & specific heat, $\mathrm{J} \mathrm{kg}^{-1} \mathrm{~K}^{-1}$ & $T_{o}$ & reference temperature, $\mathrm{K}$ \\
\hline $\begin{array}{l}d \\
\mathrm{Co}_{v, s}\end{array}$ & $\begin{array}{l}\text { diameter, } \mathrm{m} \\
\text { vapour concentration on the droplet surface, } \mathrm{kmol} \mathrm{m}^{-3}\end{array}$ & $u_{i}, u_{j}$ & $\begin{array}{l}\text { mean velocity components in } X, Y \text {, and } Z \text { directions, } \\
\mathrm{m} \mathrm{s}^{-1}\end{array}$ \\
\hline $\mathrm{Co}_{v, \infty}$ & vapour concentration in the bulk air, $\mathrm{kmol} \mathrm{m}^{-3}$ & $u_{i}^{\prime}, u_{j}^{\prime}$ & fluctuating velocity components, $\mathrm{m} \mathrm{s}^{-1}$ \\
\hline$D^{-\infty}$ & molecular diffusion coefficient, $\mathrm{m}^{2} \mathrm{~s}^{-1}$ & $u_{s}$ & superficial velocity, $\mathrm{m} \mathrm{s}^{-1}$ \\
\hline$F_{i}$ & additional forces, $\mathrm{N}$ & $v_{i}$ & velocity, $\mathrm{m} \mathrm{s}^{-1}$ \\
\hline$g$ & gravitational acceleration, $\mathrm{m} \mathrm{s}^{-2}$ & $V_{m}$ & molar volume of water, $\mathrm{m}^{3} \mathrm{~mol}^{-1}$ \\
\hline$h$ & static enthalpy, $\mathrm{J} \mathrm{kg}^{-1}$ & $x_{i}, x_{j}$ & Cartesian coordinates, $\mathrm{m}$ \\
\hline$h^{\prime}$ & fluctuating static enthalpy, $\mathrm{J} \mathrm{kg}^{-1}$ & $Y_{v}$ & vapour mass fraction \\
\hline$K$ & Darcy permeability, $\mathrm{m}^{2}$ & $Y_{v}^{\prime}$ & fluctuating vapour mass fraction \\
\hline$L$ & latent heat of condensation vaporization, $\mathrm{J} \mathrm{kg}^{-1}$ & $\beta$ & Forchheimer drag coefficient, $\mathrm{m}^{-1}$ \\
\hline$m_{d}$ & mass of discrete droplet, $\mathrm{kg}$ & $\delta_{i j}$ & kronecker delta \\
\hline$M_{w v}$ & molar mass of water vapour, $\mathrm{kg} \mathrm{kmol}^{-1}$ & $\lambda$ & molecular thermal conductivity, $\mathrm{W} \mathrm{m}^{-1} \mathrm{~K}^{-1}$ \\
\hline $\mathrm{Nu}$ & Nusselt number & $\lambda_{\text {eff }}$ & effective thermal conductivity of porous \\
\hline$p$ & pressure, Pa & & $\mathrm{W} \mathrm{m}^{-1} \mathrm{~K}^{-1}$ \\
\hline$p_{v d}$ & vapour pressure over water droplet surface, Pa & $\mu$ & dynamic viscosity, $\mathrm{kg} \mathrm{m}^{-1} \mathrm{~s}^{-1}$ \\
\hline$p_{v f}$ & vapour pressure over flat water surface, $\mathrm{Pa}$ & $\mu_{t}$ & turbulent viscosity, $\mathrm{kg} \mathrm{m}^{-1} \mathrm{~s}^{-1}$ \\
\hline$Q_{\text {res }}$ & heat of respiration, $\mathrm{W} \mathrm{m}^{-3}$ & $\sigma$ & surface tension, $\mathrm{N} \mathrm{m}^{-1}$ \\
\hline res & droplet radius, m & $\rho$ & density, $\mathrm{kg} \mathrm{m}^{-3}$ \\
\hline$R$ & universal gas constant $\left(8.314 \mathrm{~J} \mathrm{~mol}^{-1} \mathrm{~K}^{-1}\right)$ & $\phi$ & porosity \\
\hline $\operatorname{Re}$ & Reynolds number & & \\
\hline$S_{e}$ & energy source term, $\mathrm{J} \mathrm{m}^{-3} \mathrm{~s}^{-1}$ & \multicolumn{2}{|l|}{ Subscripts } \\
\hline$S_{m}$ & mass source term, $\mathrm{kg} \mathrm{m}^{-3} \mathrm{~s}^{-1}$ & $a \quad \mathrm{c}$ & continuous air phase \\
\hline$S_{u}$ & momentum source term, $\mathrm{kg} \mathrm{m}^{-2} \mathrm{~s}^{-2}$ & $d$ & discrete droplet phase \\
\hline$S h$ & Sherwood number & $p$ & product \\
\hline$t$ & time, $s$ & $i, j$ & Cartesian coordinate index \\
\hline$t_{w}$ & wall thickness, m & & \\
\hline
\end{tabular}

system, rather it focused only on some parameters that we expect could improve the system efficiency.

\section{Materials and methods}

\subsection{Humidification system and cold storage room}

This study was performed on a large chicory root cold store with a dimension of $13 \mathrm{~m}$ in length, $5.5 \mathrm{~m}$ in width and $4.2 \mathrm{~m}$ in height (Kampenhout, Belgium). The room is equipped with two cooling units that were located at the back of the room (Fig. 2). The cooling air is circulated using six fans (three fans for each cooling unit) with a diameter of $45 \mathrm{~cm}$ and total capacity of $25,200 \mathrm{~m}^{3} \mathrm{~h}^{-1}$. At the exit of the cooling unit, the air is deflected upward $\left(22^{\circ}\right)$ by using a $0.2 \mathrm{~m}$ length deflector. Six compressed air atomizer nozzles are positioned in front of the cooling units. The nozzles have a $30^{\circ}$ spray angle. The capacity of each nozzle is $5 \mathrm{~L} \mathrm{~h}^{-1}$. The water was purified using a wrapped propylene filter. The humidification system was originally set to a 10 min spraying time after every cooling cycle. The cooling cycle is determined by the storage room air setpoint temperature $\left(-2{ }^{\circ} \mathrm{C}\right)$ and the temperature difference between the incoming refrigerant and the storage room setpoint $\left(7^{\circ} \mathrm{C}\right)$. The distance between the nozzles and the cooling unit and between the nozzles and the roof were $0.6 \mathrm{~m}$ and $0.3 \mathrm{~m}$, respectively.

The room was filled with 102 chicory root bins with dimensions of $1 \mathrm{~m}$ width, $1.2 \mathrm{~m}$ depth and $1.2 \mathrm{~m}$ height; the height of the four top bins under the cooling unit was $1 \mathrm{~m}$. The bins were stacked in 4 rows. Two rows contained nine bins in three levels and the third and fourth rows (the rows near to the door) contained eight bins in three levels. Gaps between the bins along the height and depth, between the bins along the width, and between bins and walls were $0.1 \mathrm{~m}, 0.16 \mathrm{~m}$ and $0.5 \mathrm{~m}$, respectively.

\subsection{Model description}

A complete CFD model of a cool room, including product characteristics, stacking pattern, cooling unit and humidification was

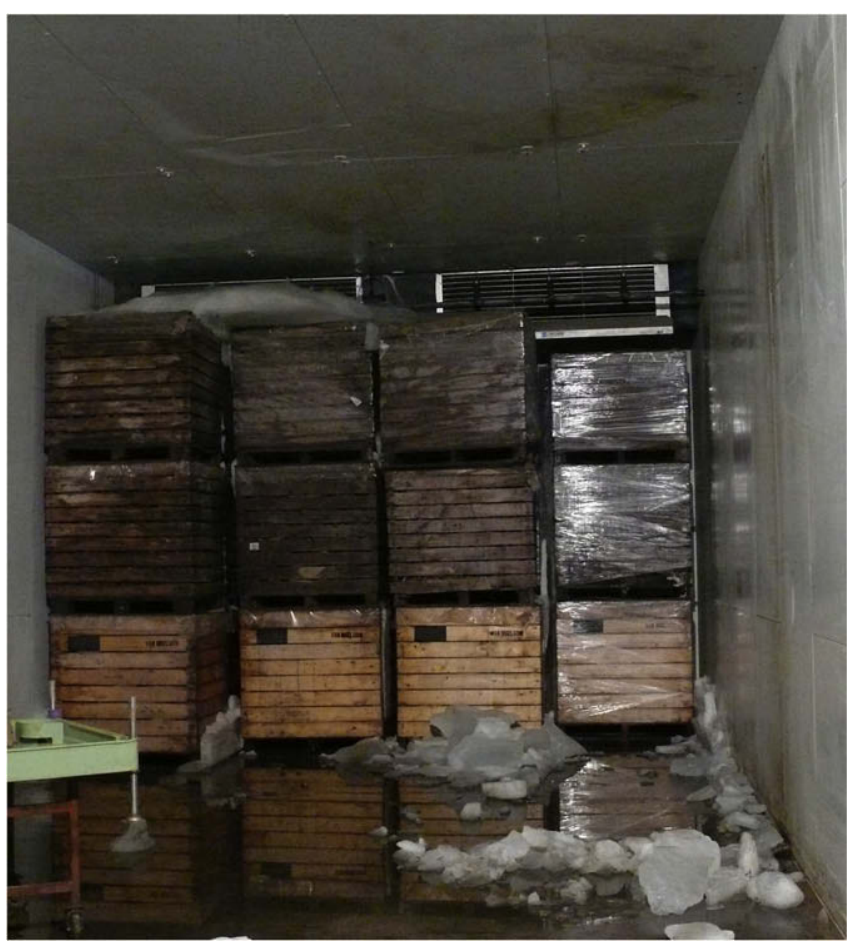

Fig. 1. Ice accumulation at different locations inside a loaded chicory root cold storage room with humidification system after a storage time of 9 months. 

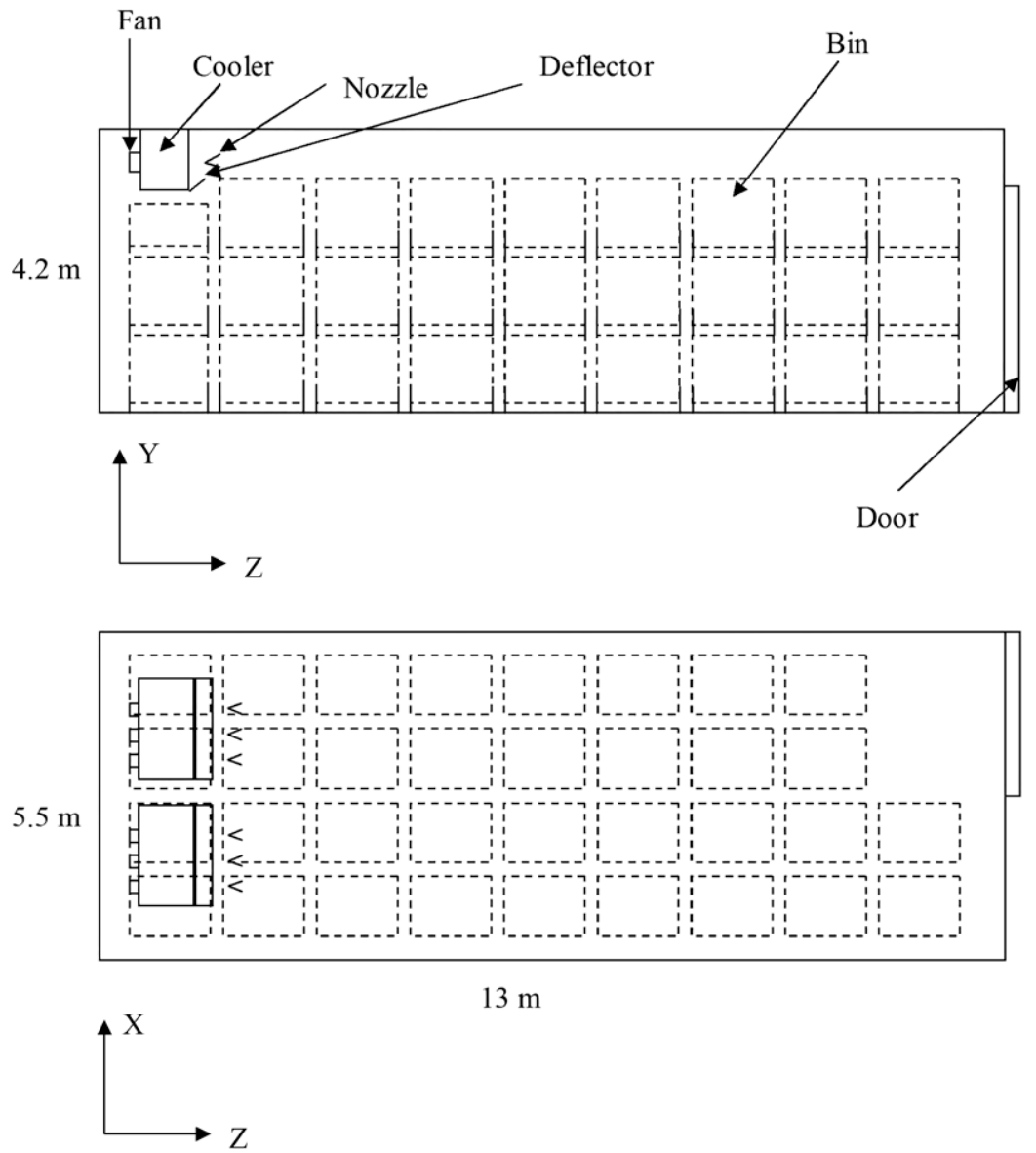

Fig. 2. Loaded chicory root cold storage room: side view (top); top view (bottom).

developed and validated using measured distributions of velocity, temperature, humidity and droplet deposition inside the cold storage room with an installed humidification system (Delele et al., 2009). An Eulerian-Lagrangian particle tracking multiphase flow model was used. The model takes into account two-way coupling with turbulent dispersion and droplet evaporation.

\subsubsection{Continuous phase}

In Cartesian coordinates, for flow in a porous media, the Reynolds-averaged fluid flow equations based on interstitial fluid velocity are as follows (Nakayama and Kuwahara, 1999; Antohe and Lage, 1997):

$\frac{\partial\left(\rho_{a}\right)}{\partial t}+\frac{\partial\left(\rho_{a} u_{i}\right)}{\partial x_{i}}=S_{m}$

$\frac{\partial\left(\rho_{a} u_{i}\right)}{\partial t}+\frac{\partial\left(\rho_{a} u_{i} u_{j}\right)}{\partial x_{j}}=\frac{\partial(p)}{\partial x_{i}}+\frac{\partial}{\partial x_{j}}\left[\mu_{a}\left(\frac{\partial\left(u_{i}\right)}{\partial x_{j}}+\frac{\partial\left(u_{j}\right)}{\partial x_{i}}\right)\right]$

$$
-\frac{\partial}{\partial x_{j}}\left(\rho_{a} \overline{u_{i}^{\prime} u_{j}^{\prime}}\right)-\delta_{i 3}\left[1-\alpha\left(T-T_{o}\right)\right] \rho_{a} g+S_{u}
$$

By assuming a local thermal equilibrium between the air and the porous solid matrix (the temperature of the air and the porous solid matrix is assumed to be equal), the energy equation is:

$$
\begin{gathered}
\frac{\partial}{\partial t}\left(\phi \rho_{a} C_{p a} T+(1-\phi) \rho_{p} C_{p p} T\right)+\phi \frac{\partial}{x_{j}}\left(\rho_{a} C_{p a} u_{j} T\right) \\
=\frac{\partial}{\partial x_{j}}\left[\lambda_{e f f}\left(\frac{\partial T}{\partial x_{j}}\right)\right]-\phi \frac{\partial}{\partial x_{j}}\left(\rho_{a} C_{p a} \overline{u^{\prime} T^{\prime}}\right)+S_{e}
\end{gathered}
$$

In most cases of flow in fluid saturated porous media the assumption of local thermal equilibrium is valid (Nakayama and Kuwahara,
2005); and, this assumption has been used by several previous studies (Nakayama and Kuwahara, 1999; Antohe and Lage, 1997; Masuoka and Takatsu, 1996; Chourasia and Goswami, 2007). Using scale analysis, van der Sman (2008) reported that this thermal equilibrium assumption is valid when the particle Reynolds number, $R e_{p}=\frac{\rho_{a} u_{s} d_{p}}{\mu_{a}}<10^{3}$. The transport equation for vapour mass fraction is:

$$
\begin{aligned}
\phi \frac{\partial\left(\rho_{a} Y_{v}\right)}{\partial t}+\phi \frac{\partial}{\partial x_{j}}\left(\rho_{a} u_{j} Y_{v}\right)= & \phi \frac{\partial}{\partial x_{j}}\left[\rho_{a} D_{a}\left(\frac{\partial\left(Y_{v}\right)}{\partial x_{j}}\right)\right] \\
& -\phi \frac{\partial}{\partial x_{j}}\left(\rho_{a} \overline{u_{j}^{\prime} Y^{\prime}}\right)+S_{m}
\end{aligned}
$$

The details about the calculation of the specific Reynolds stress term $\left(\overline{u_{i}^{\prime} u_{j}^{\prime}}\right)$ in Eq. (3) and the specific Reynolds flux terms $\overline{u_{j}^{\prime} T^{\prime}}$ and $\overline{u_{j}^{\prime} Y_{v}^{\prime}}$ in Eqs. (4) and (5) and other parameters can be found in Delele et al. (2009).

The term $S_{m}$ takes into account the evaporation from the discrete droplet phase and product surface and the condensation/ evaporation of water vapour on the cooling coils. The term $S_{u}$ contains the resistance of the porous media to airflow and the momentum exchange with the discrete phase. The term $S_{e}$ consists of the heat exchange on the cooler, the heat exchange with the discrete phase, the heat of respiration of the product and the heat of evaporation/condensation of water vapour. The details about the calculation of these terms can be found in Delele et al. (2009).

\subsubsection{Discrete phase}

For a discrete droplet travelling in a continuous fluid medium, the forces acting on the droplet which affect the droplet accelera- 
tion are due to the difference in velocity between the droplet and the fluid, and due to the displacement of the fluid particle. Neglecting all other forces except the drag and buoyancy forces, the equation of motion for the droplet can be written as:

$m_{d} \frac{d v_{d i}}{d t}=\frac{1}{8} \pi \rho_{a} d^{2} C_{d}\left|v_{a j}-v_{d j}\right|\left(v_{a i}-v_{d i}\right)+\frac{1}{6} \pi d^{3}\left(\rho_{d}-\rho_{a}\right) g_{i}+F_{i}$

The first and the second terms in the right hand side represent the drag and buoyancy forces, respectively. The drag coefficient $\left(C_{d}\right)$ was calculated using an empirical correlation developed by Haider and Levenspiel (1989). The detail about the calculation of $C_{d}$ can be found in Delele et al. (2009). In this correlation the effect of wall boundaries on drag force was not included. This effect can be included using Faxen (Faxen, 1922) expression. However, based on the accuracy of the validated model of Delele et al. (2009), it was reasonable to neglect such wall boundary effect. $F_{i}$ represents the additional forces that include the lift force. Flow shear causes a lift force; this can be calculated using Saffman expression (Saffman, 1965; Li and Ahmadi, 1992). This form of the lift force is intended for small particle Reynolds numbers. Also, the particle Reynolds number based on the particle-fluid velocity difference must be smaller than the square root of the particle Reynolds number based on the shear field. This restriction is valid for submicron particles; as a result, it is recommended to use this option only for submicron particles. Since the size of the droplets that were dealt in this study was higher than submicron, the lift force was neglected.

The heat balance that relates the sensible heat change in the droplet to the convective and latent heat transfer between the droplet and the continuous phase reads:

$m_{d} C_{p d} \frac{d T_{d}}{d t}=\pi d N u \lambda_{a}\left(T_{a}-T_{d}\right)+L\left(\frac{d m_{d}}{d t}\right)$

For a droplet below its boiling point, the rate of evaporation of the droplets to the air is governed by gradient diffusion:

$\frac{d m_{d}}{d t}=-\pi d D_{a} \operatorname{ShM}_{w v}\left(\mathrm{Co}_{v, s}-C_{v, \infty}\right)$

The details about the determination of the drag coefficient $\left(C_{d}\right)$, droplet position, turbulent dispersion, Nusselt number $(\mathrm{Nu})$, Sherwood number $(S h)$ and droplet source terms are available in Delele et al. (2009). At this storage temperature $\left(-2^{\circ} \mathrm{C}\right)$, the droplets are

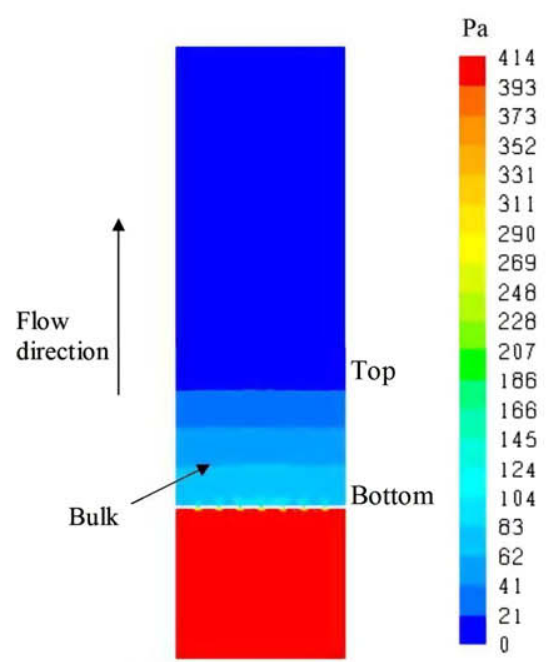

(a)

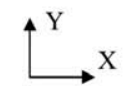

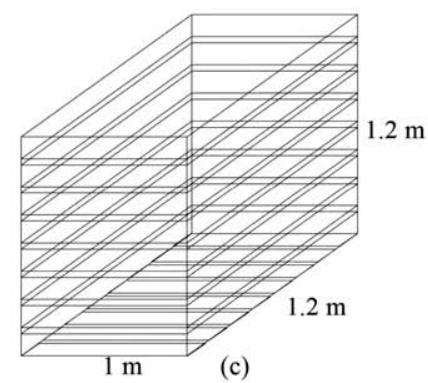

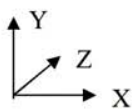

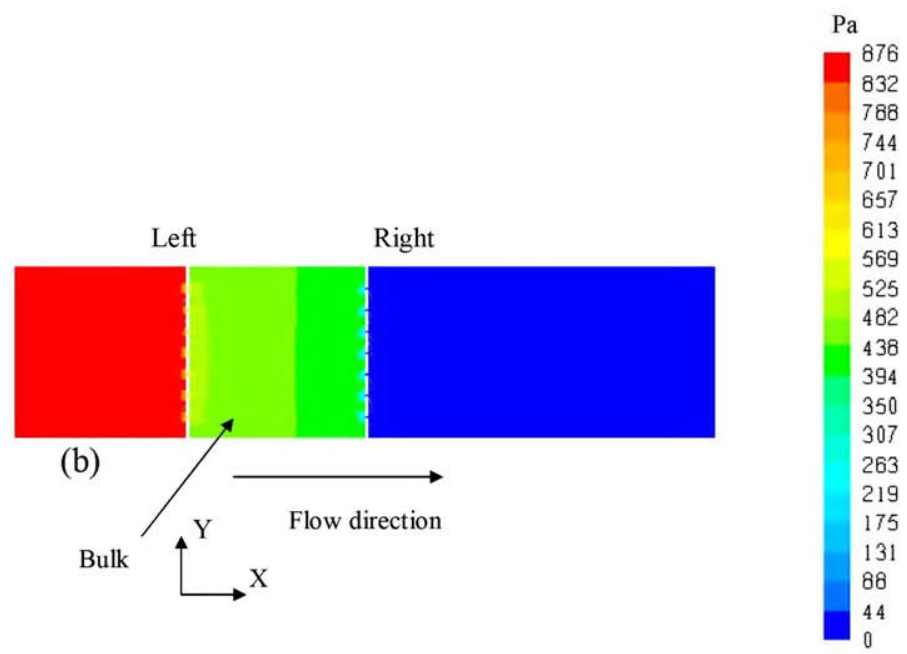

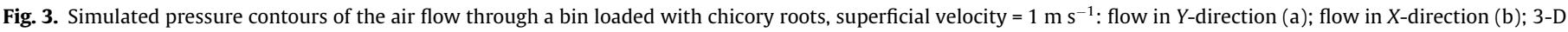
drawing of vented bin (c). 
Table 1

Parameters of the Darcy-Forchheimer equation for vented bins loaded with chicory root, obtained from CFD simulations.

\begin{tabular}{llr}
\hline Direction & $\frac{1}{K}\left(1 / \mathrm{m}^{2}\right)$ & $\beta(1 / \mathrm{m})$ \\
\hline$X$-direction & 343528.3 & 1309.1 \\
$Y$-direction & 337089.7 & 615.8 \\
$Z$-direction & 339700.1 & 1311.4 \\
\hline
\end{tabular}

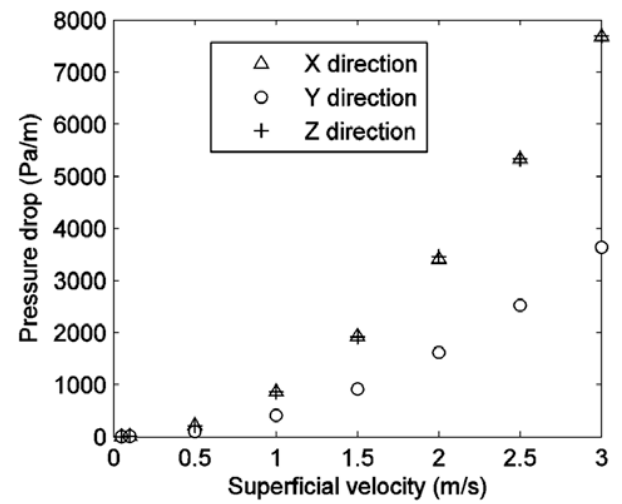

Fig. 4. Simulated pressure drop as a function of superficial velocity (with a mean value of $1.33 \mathrm{~m} \mathrm{~s}^{-1}$ ) of the air flow through a bin loaded with chicory root

assumed to be in liquid state. Freezing of droplets is a four stage process (Hindmarsh et al., 2003; Al-Hakim et al., 2006): first, a precooling or supercooling stage, in which the droplet is cooled from the initial injection temperature (in this study, $10^{\circ} \mathrm{C}$ ) to below the equilibrium freezing temperature, until crystal nucleation occur; second, a recalescence stage where supercooling is terminated, crystal growth occurs and the droplets heated up to the equilibrium freezing temperature; third, a freezing stage where growth of the crystal continues at the equilibrium freezing point; and the fourth stage is the a cooling stage in which the solid droplet temperature is reduced to the near ambient air temperature. The nucleation and freezing temperatures of distilled water droplets with diameter 2-1500 $\mu \mathrm{m}$ was reported to be around $-20^{\circ} \mathrm{C}$ and $0{ }^{\circ} \mathrm{C}$, respectively (Hindmarsh et al., 2003; Al-Hakim et al., 2006). In this study, minimum cooling air temperature of $-2.5^{\circ} \mathrm{C}$ and purified water were used, this temperature is very much higher than the reported nucleation temperature; this shows the validity of the above assumption that was made about the state of the droplets.

\subsection{Solution procedure}

The CFD code used for this work was Fluent 6.3.28 (Fluent Inc., Lebanon, USA). The cold store model consisted of the loaded bins, the fans and the cooler (Fig. 2). The fans were modelled as a fan boundary with a pressure rise of $92 \mathrm{~Pa}$ that was the characteristics of the fan corresponded to $4200 \mathrm{~m}^{3} \mathrm{~h}^{-1}$, this was a lumped parameter model that did not give the detail flow behaviour through the fan blades but predicted the amount of flow through the fan. Tetrahedral hybrid mesh element sizes with a maximum edge length of $0.03 \mathrm{~m}$ for the fan surface and air gap regions, and 0.1 for the other were used. The total number of elements was 1,574,249. On the floor of the room and the walls that were exposed to the atmosphere, a heat flux $\left(q_{f w}=\frac{\lambda_{w}}{t_{w}}\left(T_{w}-T\right)\right)$ from outside to the inside was applied. The outside wall/soil below the concrete floor temperature $T_{w}$ was assumed to be the yearly average external temperature in Belgium $\left(10^{\circ} \mathrm{C}\right.$ ) (Anciaux et al., 2006); the thermal conductivity $\lambda_{w}$ of the insulation wall and the concrete floor were
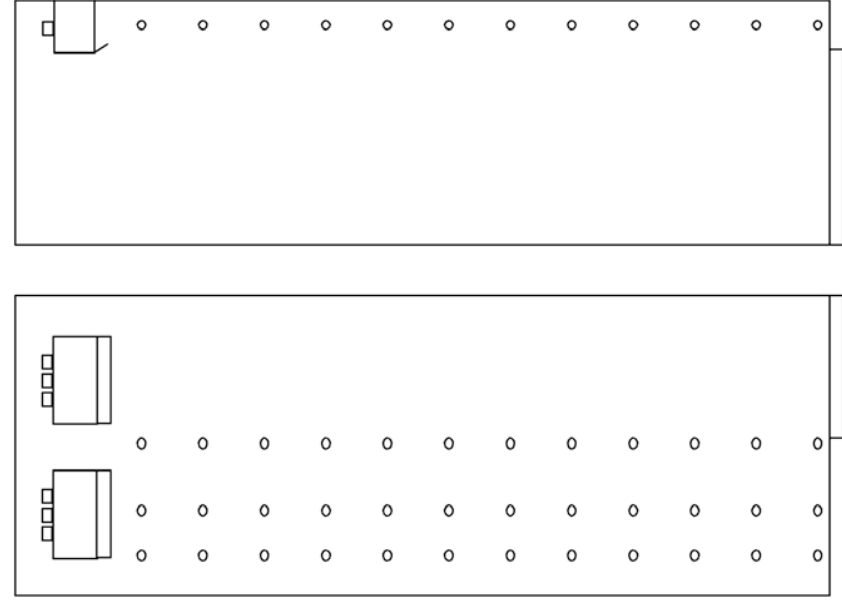

Fig. 5. Experimental set up for measuring velocity of the air jet coming from the cooler; side view (top), top view (bottom); (o) measurement positions.

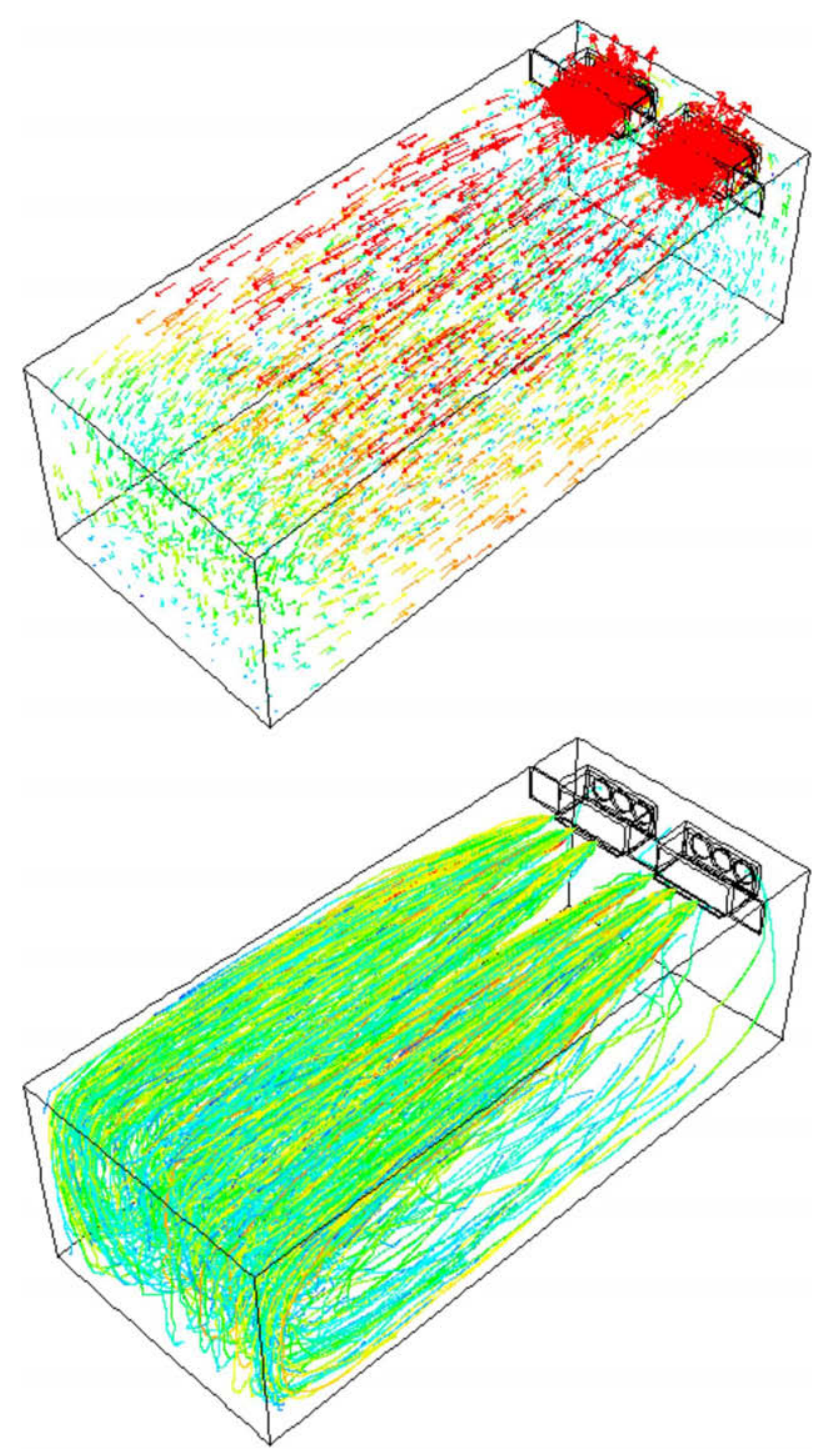

Fig. 6. Air velocity vectors (top) and tracks of sprayed droplets (bottom) for an empty chicory root cold storage room, with a deflector length of $0.2 \mathrm{~m}$ : velocity vector: $2 \mathrm{~m} \mathrm{~s}^{-1}$ (red), $0 \mathrm{~m} \mathrm{~s}^{-1}$ (blue); droplet diameter: $18.5 \mu \mathrm{m}$ (red), $2.5 \mu \mathrm{m}$ (blue). 
0.022 and $2.6 \mathrm{~W} \mathrm{~m}^{-1} \mathrm{~K}^{-1}$, respectively; the thickness $t_{w}$ of the insulation wall and the concrete floor were 0.12 and $0.1 \mathrm{~m}$, respectively.

The droplets were injected using the spray atomization model (Anon, 2006). The predicted values of $D_{v 10}, D_{v 50}$ and $D_{v 90}$ (diameters at which the volume fraction of $10 \%, 50 \%$, and $90 \%$ is made up of droplets with diameters smaller than this value) are $7.3 \mu \mathrm{m}, 12.2 \mu \mathrm{m}$ and $17.6 \mu \mathrm{m}$, respectively. The curvature of small droplets increases the vapour pressure over the droplet surface as expressed by Kelvin equation $\left(\frac{p_{v d}}{p_{d f}}=\exp \left(\frac{2 \sigma V_{m}}{r R T_{d}}\right)\right)$. Based on the mean droplet size, the percentage of supersaturation $\left(\left(\frac{p_{v d}}{p_{s f}}-1\right) \times 100\right)$ was very small (for instance, $0.019 \%$ at the storage temperature of $-2{ }^{\circ} \mathrm{C}$ ). As a result this supersaturation effect was neglected. The droplets that collide with the walls were assumed to be trapped. The model did not consider the evaporation/sublimation from the surface of the deposit. The accuracy of the validated model that was applied in this study showed the validity of this assumption (Delele et al., 2009). The effect of the deposit on the flow was not taken into account. The heat of respiration $\left(\mathrm{W} \mathrm{m}^{-3}\right)$ of chicory root $\left(Q_{\text {res }}=37.22 e^{0.054\left(T_{p}-273\right)}\right)$ was taken from Anon

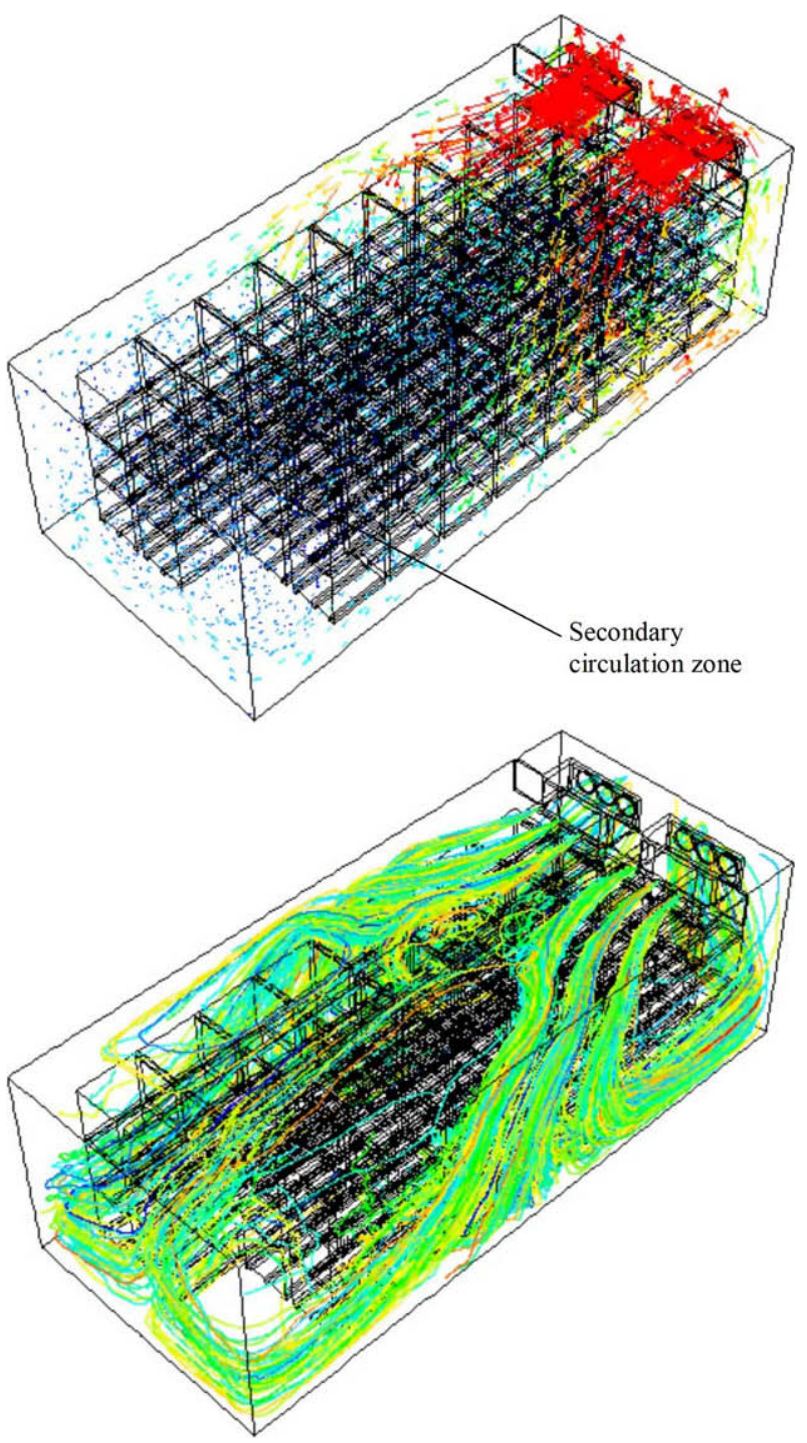

Fig. 7. Air velocity vectors (top) and tracks of sprayed droplets (bottom) for loaded chicory root cold storage room, with a deflector length of $0.2 \mathrm{~m}$ : velocity vector: $2 \mathrm{~m} \mathrm{~s}^{-1}$ (red), $0 \mathrm{~m} \mathrm{~s}^{-1}$ (blue); droplet diameter: $18.5 \mu \mathrm{m}$ (red), $2.5 \mu \mathrm{m}$ (blue).
(1980); where, $Q_{r e s}$ is the heat of respiration and $T_{p}$ is the product temperature $(\mathrm{K})$. The moisture loss was calculated using a lumped convection model, neglecting the moisture diffusion inside the chicory root, the detailed equations are given in Delele et al. (2009).

The pressure loss coefficients of the flow through a bulk of chicory root handled in vented bins were approximated using a separate CFD simulation. The simulation was done for a single vented bin that took into account the details of the bin slots and the bulk of chicory roots in the bin. The computational domain was discretised using a tetrahedral hybrid mesh. Meshes with a maximum edge length of $0.005 \mathrm{~m}$ and $0.05 \mathrm{~m}$ for the slot surfaces and volume, respectively were used. The total number of cells was in the range of 668,890-993,940 depending on the flow direction that was analysed. The bulk in the bin was assumed as a porous medium, and the pressure loss was expressed in the form of Darcy-Forchheimer equation $\left(\nabla p=-\frac{\mu}{K} u_{s}-\frac{1}{2} \beta \rho\left|u_{s}\right| u_{s}\right)$ (Forchheimer, 1901). For the porosity $(\phi)$ and the loss coefficients $\left(\frac{1}{K}\right.$ and $\beta$ ) of the flow through the porous bulk of chicory roots, the values from Hoang et al. (2003) were taken $(\phi=0.49$,
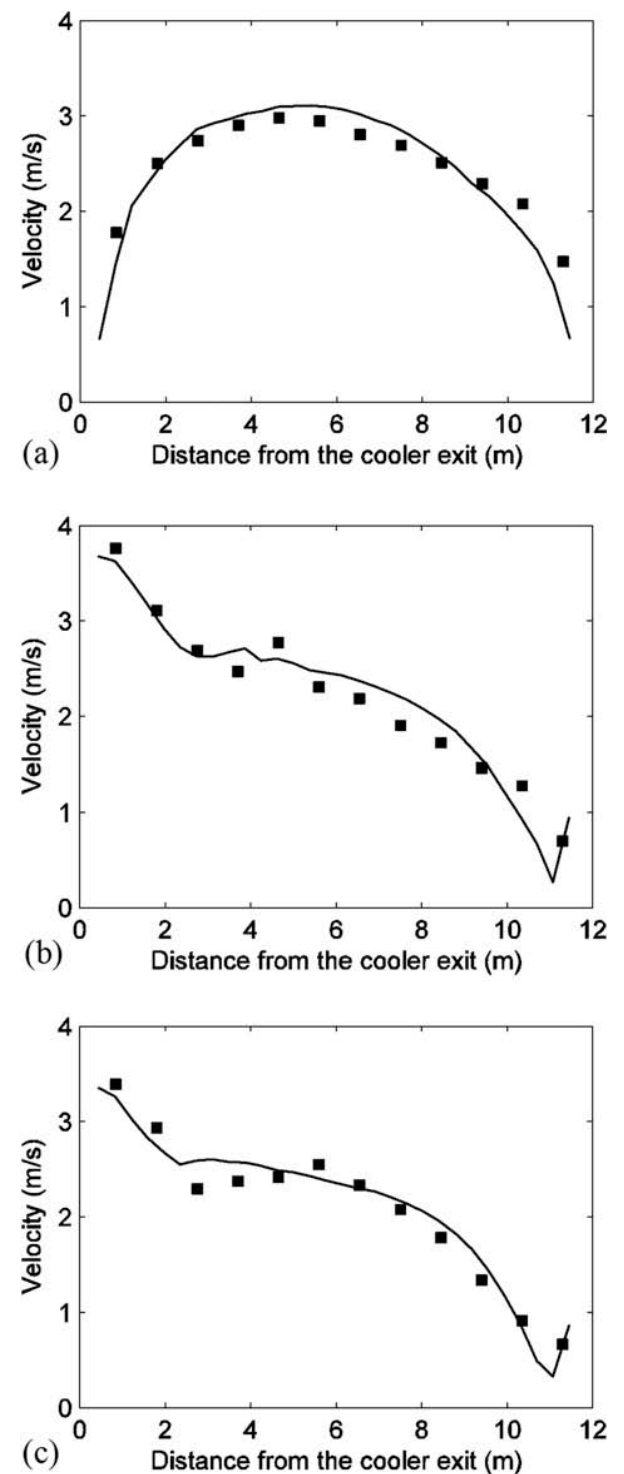

Fig. 8. Measured ( $\square$ ) and predicted (-) cooling air velocity at different positions (Fig. 5), with a $0.4 \mathrm{~m}$ air deflector: (a) along the centre of the room; (b) along the centre of the cooler; (c) along a distance of $0.85 \mathrm{~m}$ from the wall. 
$\left.\frac{1}{K}=335,0001 / \mathrm{m}^{2}, \quad \beta=117.91 / \mathrm{m}\right)$. A typical simulation result is shown in Fig. 3. The calculated anisotropic loss coefficients are given in Table 1 . These loss coefficients were determined from Fig. 4. The pressure drop per unit length for a flow in the $X$ (side to side) and $Z$ (front to back) directions were almost similar. The pressure drop per unit length in the $Y$ direction was lower than the other two directions, this is the contribution of the top open side of the bin.

For closure of the Reynolds-averaged fluid flow equations, the SST turbulence model was used. All the equations were discretized using the second order upwind scheme. The solution converged to a normalized root mean square residual below $10^{-4}$ of all equations. The calculation was performed using a Pentium IV, 3.21 GHz WinXp workstation with 3.62 GB Ram.

Simulations were performed using the following approach: first, a steady state simulation of the storage room air velocity, temperature and humidity distributions was performed. Second, using the result from the steady state simulation as an initial condition, a transient simulation of the storage room with an active humidification system was performed. The duration of simulation was equal to the duration of one humidification period, which was a variable in this study.

\subsection{Validation method}

Since this paper applied the validated model that was developed in Delele et al. (2009), a detailed validation experiment was not performed. The room dynamics was evaluated by measuring the air jet velocity that was coming out of the cooling unit in to the room. It has been shown previously that the air jet velocity profile is the most important factor that affects the dispersion of the sprayed droplets (Delele et al., 2009). In the empty chicory root cold storage room, the velocity of the air jet was measured at different horizontal positions at $0.3 \mathrm{~m}$ below the roof of the room

(Fig. 5). The air velocity magnitude was measured using an air velocity transducer (TSI Incorporated, MN, USA). The operating range of the sensor is $0.125 \mathrm{~m} / \mathrm{s}$ to $50 \mathrm{~m} / \mathrm{s}$. The factory calibrated accuracy of the sensor is $2 \%$ of the reading or $0.5 \%$ of the full range. Starting from $0.85 \mathrm{~m}$ from cooler exit, the measurements were taken at $0.95 \mathrm{~m}$ intervals along the length of the room. Along the room width, the measurements were taken at centre of the room, at the centre of the cooler and $0.85 \mathrm{~m}$ from the wall of the room. By assuming symmetry, the measurement was done only in one half of the room.

\subsection{Design study}

In practice, it was observed that ice accumulated on the chicory root bins and on the floor (Fig. 1). Clearly, the humidification system in this cold store is currently not operating optimally. Here, we want to explore different measures to improve humidification in terms of both room design modifications and operating parameters of the humidification system. In particular, we have selected the following aspects for investigation. Our aim is to provide a humidity level of $95 \% \mathrm{RH}$ or more in the entire room, while minimizing surface deposition of the sprayed water droplets. The effects of the following parameters were evaluated:

- Deflector length: the deflector length was increased from the existing $0.2 \mathrm{~m}$ to $0.4 \mathrm{~m}, 0.6 \mathrm{~m}$, and $0.8 \mathrm{~m}$. We expect that deflector length affects the penetration length of the air from the cooler into the room.

- Height of the stack: by replacing all the top bins with the bins that had a height of $1 \mathrm{~m}$ (similar to the top bins under the cooling unit), the height of the stack was decreased from the existing $3.6 \mathrm{~m}$ to $3.4 \mathrm{~m}$. A lower height provides more free air for droplet evaporation.
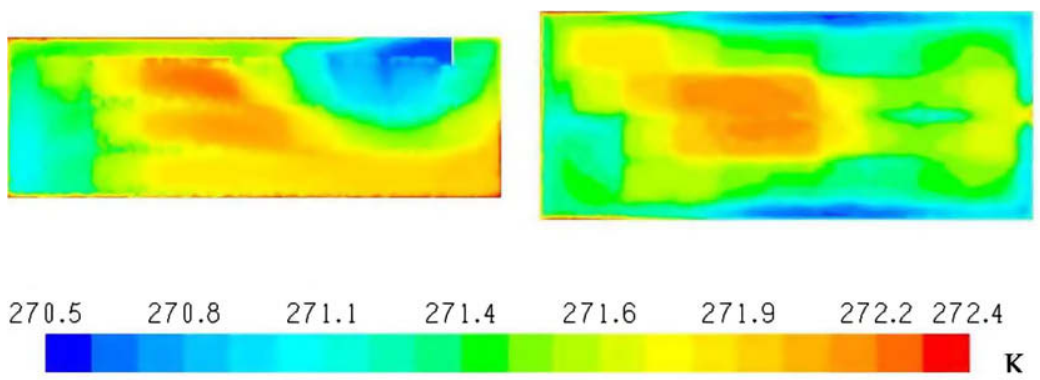

(a)
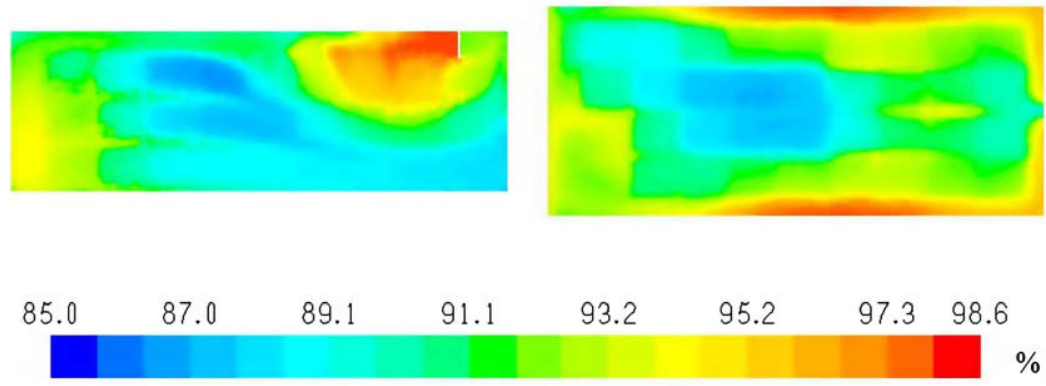

(b)

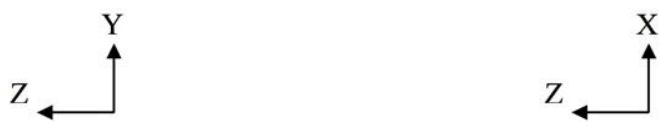

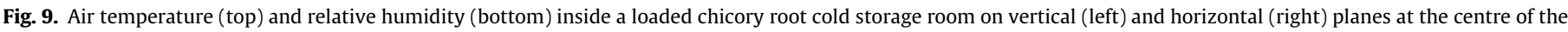
room: (a) Temperature (b) Humidity; simulation without humidification. 
Table 2

Amount of sprayed droplet deposited on the stack and room surfaces, sucked by the fan and evaporated after different duration of humidification time, for a deflector length of $0.2 \mathrm{~m}$.

\begin{tabular}{llllll}
\hline $\begin{array}{l}\text { Number } \\
\text { of nozzles }\end{array}$ & $\begin{array}{l}\text { Spraying } \\
\text { time }(\mathrm{min})\end{array}$ & \multicolumn{2}{l}{ Weight percent (\%) } \\
\cline { 3 - 5 } & & \multicolumn{2}{l}{ Deposited } & Evaporated \\
\cline { 3 - 5 } & & Stack & Room & Cooler & \\
\hline 6 & 0.5 & 3.10 & 3.57 & 0.01 & 93.31 \\
6 & 1 & 5.80 & 6.08 & 3.22 & 84.84 \\
6 & 2 & 9.06 & 8.07 & 4.84 & 78.03 \\
2 & 1.5 & 1.96 & 1.25 & 0 & 96.79 \\
\hline
\end{tabular}

- The model was used to evaluate different humidifier spraying periods after every cooling cycle. This was done using the original six nozzles with a spraying rate of $5 \mathrm{~L} \mathrm{~h}^{-1}$ per nozzle. Shortening spraying periods will reduce the unwanted surface deposition.

- Number of nozzles.

\section{Results and discussion}

\subsection{Cooling air velocity distribution and sprayed droplets dispersion}

For both the empty and loaded chicory cold store, the air velocity vectors and the droplet tracks are given in Figs. 6 and 7, respectively. There was a good agreement between the measured and predicted velocity distribution of the air jet that was exited from the cooler (Fig. 8). In an empty room, the high velocity air jet from the cooling unit is attached to the ceiling (Coanda effect) for a long- er distance than in the loaded room. This has considerable consequences for both uniform cooling and droplet dispersion. In the loaded room, the jet deflects easily and short circuits to the fan and creates a secondary circulation zone where one can expect a poor cooling effect. Moureh et al. (2002) and Moureh and Flick (2004) reported similar results with respect to the effect of the load on the air path; in $13 \mathrm{~m}$ long, empty and loaded truck, the air jet was separated from the ceiling at approximately $10 \mathrm{~m}$ and $5 \mathrm{~m}$, respectively (Moureh et al., 2002). Based on the predicted average superficial velocity of the cooling air inside the load, $0.024 \mathrm{~m} \mathrm{~s}^{-1}$ and effective diameter of chicory root, $0.0896 \mathrm{~m}$ (Verboven et al., 2004), the particle Reynolds number was calculated and found to be 161.3. This shows the validity of the local thermal equilibrium assumption that was made in this study.

Most of the droplets were following the direction of the high velocity cold air jet (Figs. 6 and 7). A similar result was reported in Delele et al. (2009) for a small scale cool room.

\subsection{Room temperature and relative humidity distribution}

First, it is important to understand the dynamics of temperature and humidity in the room for a particular configuration. Simulations are therefore performed in the loaded room without humidification.

The short circuiting affected the temperature and $\mathrm{RH}$ distributions of the storage room (Fig. 9). For the loaded room at a steady storage condition without humidification, the hottest spot was located in the secondary circulation zone near the top rear side of the room, where the velocity of the cooling air was the lowest. There was a difference of $1.7^{\circ} \mathrm{C}$ between the coldest and the hottest spot in the room. This shows that the low velocity cooling air towards the rear side of the room was not able to completely

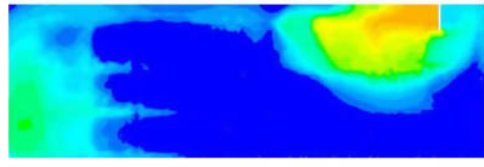

(a)

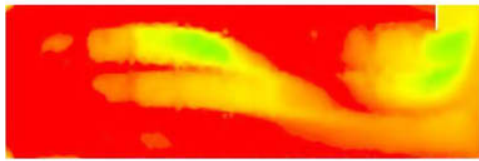

(b)
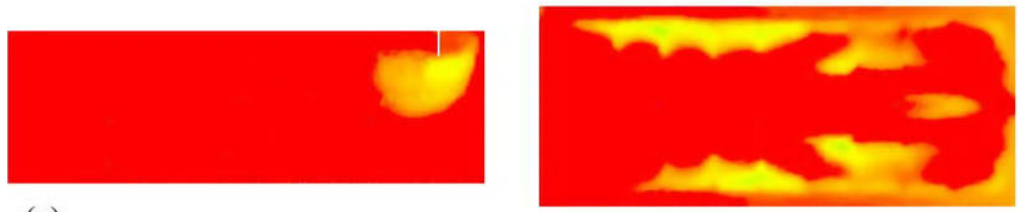

(c)
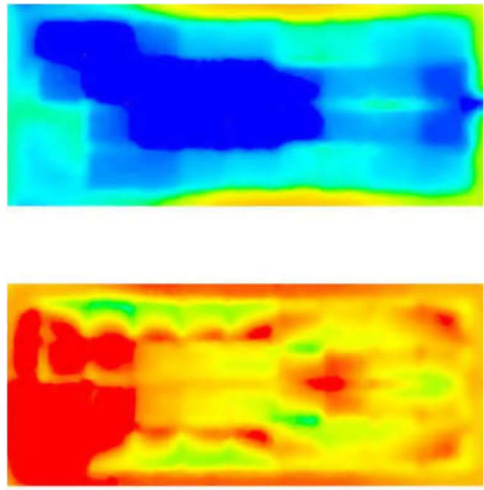

96.0

97.5

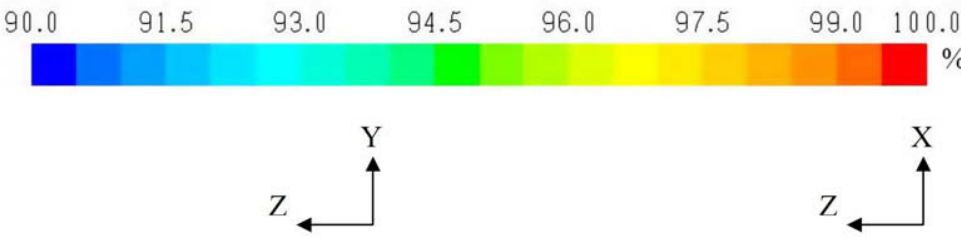

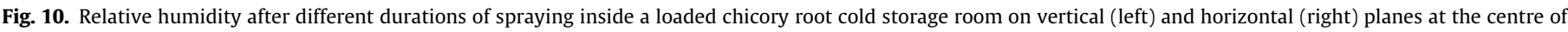
the room, blue zone corresponds to $90 \%$ RH or less: (a) 0 min humidification; (b) 0.5 min humidification; (c) 1 min humidification. 


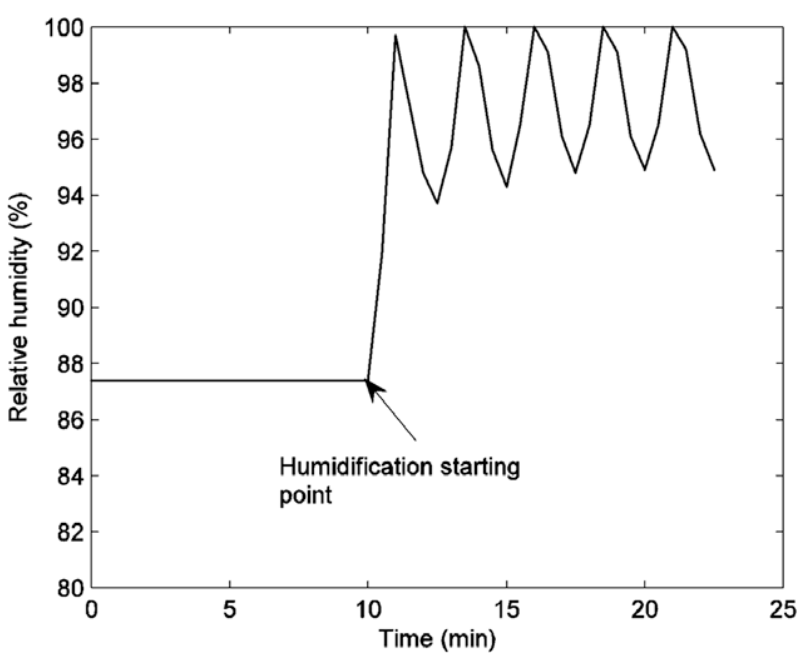

Fig. 11. Relative humidity at the hottest spot inside the loaded cold chicory root storage room with an interval humidification of $0.5 \mathrm{~min}$ on and $2 \mathrm{~min}$ off cycle.

remove the heat of respiration of the product. Furthermore, the zone of lowest $\mathrm{RH}$ is exactly in this area, which may cause excessive dehydration of the roots. There was a $\mathrm{RH}$ difference of $11.2 \%$ between the coldest and the hottest spot in the room. Similarly, Moureh and Flick (2004) reported such effects at the rear side of a loaded truck and found a difference as large as $12^{\circ} \mathrm{C}$ between the maximum and minimum temperatures. The humidity contours reveal very low humidity inside the bulk area and values below $95 \%$ in most areas in the room. Clearly, humidification is required.

\subsection{Evaluation of the humidification period}

We expected that 10 min of humidification would be longer than required for an efficient process. Adding more water than required will result in excessive deposition of the sprayed water droplets on the product and room surfaces; due to the sub-zero storage condition, these deposited water droplets will change and accumulated into ice as was observed in practice. We decided therefore to study the effects of $0.5,1$ and 2 min of humidification.

After $0.5,1$ and 2 min continuous humidification of the loaded cold storage room that was at steady storage condition initially, the amounts of sprayed droplet that was deposited on the stack, deposited on the room surfaces, deposited in the cooler unit and evaporated were quantified (Table 2). In order to give time for the suspended droplets either to deposit on the surfaces or evapo-

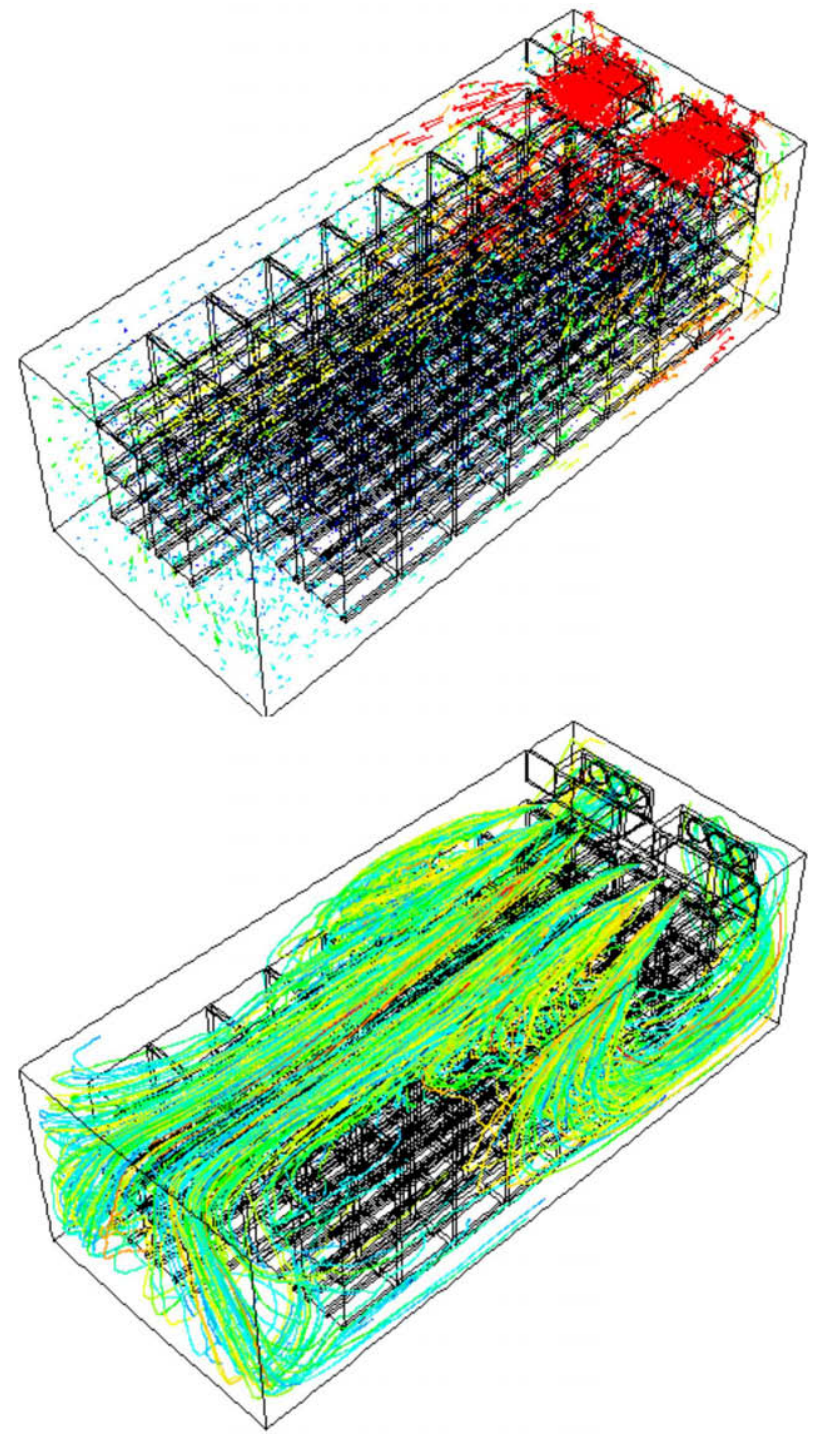

Fig. 13. Air velocity vectors (top) and tracks of sprayed droplets (bottom) for loaded chicory root cold storage room for a deflector length of $0.8 \mathrm{~m}$ : velocity vector: $2 \mathrm{~m} \mathrm{~s}^{-1}$ (red), $0 \mathrm{~m} \mathrm{~s}^{-1}$ (blue); droplet diameter: $18.5 \mu \mathrm{m}$ (red), $2.5 \mu \mathrm{m}$ (blue).

rate completely, each simulated humidification period was followed by a dead time of $1 \mathrm{~min}$ without humidification. An increase of the spraying time increased the non-evaporated portion that was deposited. After 0.5 min of continuous humidification
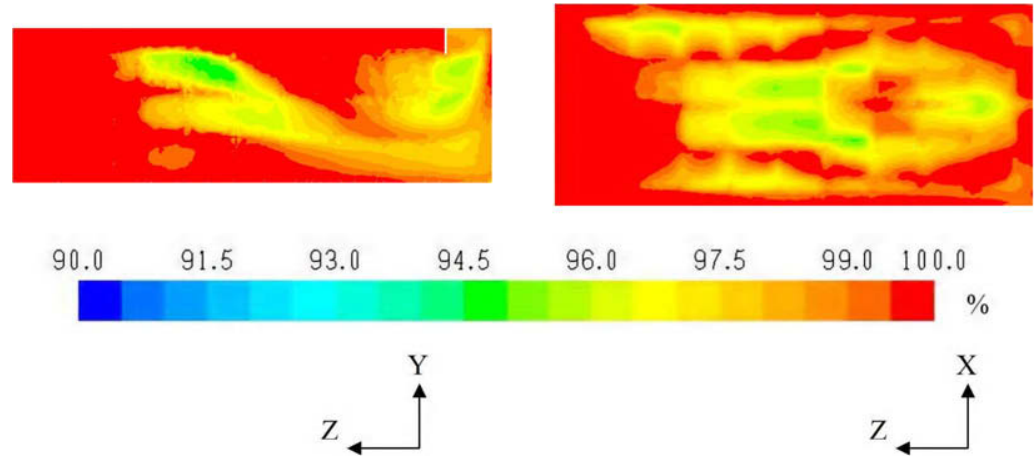

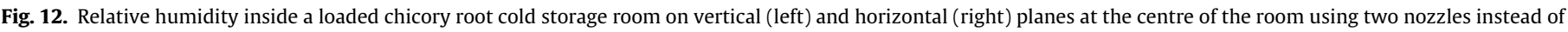
six, and with a spraying time of $1.5 \mathrm{~min}$. 

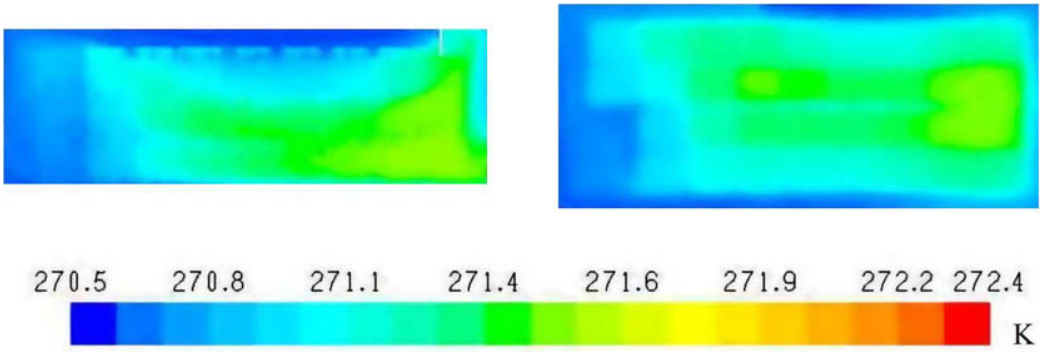

(a)
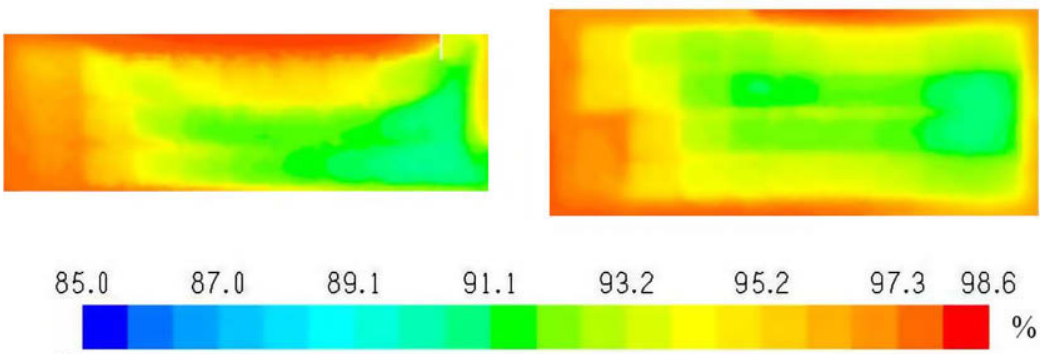

(b)

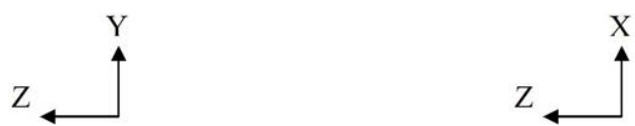

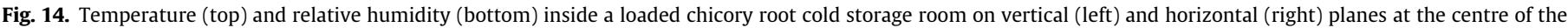
room for a deflector length of $0.8 \mathrm{~m}$ : (a) temperature (b) humidity; simulation without humidification.

there was only a small non-evaporated portion (6.7\%), but after 2 min of continuous humidification the non-evaporated portion increased already to $22.0 \%$.

The humidity of the room at the centre vertical and horizontal planes after $0,0.5$ and $1 \mathrm{~min}$ of continuous humidification followed by $1 \mathrm{~min}$ of no humidification time is given in Fig. 10 . With the existing six nozzles, after 0.5 min of humidification time the humidity in room was greater than $95 \%$ (even saturated in some regions). This saturation was the reason for the increase of the non-evaporated portion of the sprayed droplets with spraying time. With the existing six nozzles, an interval humidification of 0.5 min on and 2 min off time maintained the required humidity level (95-100\%) (Fig. 11). This shows that the existing spraying time of 10 min after every cooling cycle clearly is too much and an interval humidification of $0.5 \mathrm{~min}$ on and $2 \mathrm{~min}$ of cycle could give a better result.

\subsection{Evaluation of the number of nozzles}

Next, a simulation was done with two nozzles instead of the original six nozzles. We also expected that the other option to decrease the unwanted deposition of the sprayed droplets is to use a lower number of nozzles. With $1.5 \mathrm{~min}$ of humidification using two nozzles, it was possible to achieve an $\mathrm{RH}$ level that was equivalent to the one with $0.5 \mathrm{~min}$ of spraying using the original six nozzles (Fig. 12). By using two nozzles instead of six it was possible to decrease the unwanted deposition of sprayed droplets and increase the amount evaporated (Table 2). Using this two nozzle setup, with an interval humidification of $1.5 \mathrm{~min}$ on and 2 min off time it was also possible to maintain the humidity level above $95 \%$. A small number of nozzles with longer humidification time can give the required RH level with a smaller amount of surface deposition.

\subsection{Effect of air deflector length}

Elongating the deflector length increased the tendency of the cold air-jet and the sprayed droplets to reach the far end side of the stack (compare Fig. 13 with Fig. 7). The elongation of the deflector slightly increased the static pressure of the cold air at the exit of the cooler around the deflector (by changing from $0.2 \mathrm{~m}$ to $0.8 \mathrm{~m}$ there was an increase of about $1.6 \mathrm{~Pa}$ ), which is low compared to the pressure rise of the fan (92 Pa). This small increase in pressure, however, did not affect the fan flow rate. The deflectors affected the room temperature and relative humidity distributions (compare Fig. 14 with Fig. 9), beneficially, even without humidification. Longer deflectors clearly improve the uniformity of the room temperature and relative humidity. For a deflector length of $0.8 \mathrm{~m}$, the temperature difference between the coldest and the hottest point was decreased to $0.9^{\circ} \mathrm{C}$ (originally $1.7^{\circ} \mathrm{C}$ ), and the lowest $\mathrm{RH}$ increased to $90.8 \%$ (originally $86.4 \%$ ). Due to the increase in penetration length of the cold air jet, increasing the deflector length will also improve the cooling rate of the room.

\section{Table 3}

Amount of sprayed droplet deposited on the stack and room surfaces, sucked by the fan and evaporated for different air deflector lengths after $0.5 \mathrm{~min}$ of continuous humidification using six nozzles.

\begin{tabular}{lllll}
\hline Deflector length $(\mathrm{m})$ & \multicolumn{2}{l}{ Weight percent $(\%)$} & \\
\cline { 2 - 4 } & \multicolumn{2}{l}{ Deposited } & & Evaporated \\
\cline { 2 - 4 } & Stack & Room & Cooler & \\
\hline 0.2 & 3.10 & 3.57 & 0.01 & 93.31 \\
0.4 & 2.84 & 3.14 & 0.007 & 93.97 \\
0.6 & 2.76 & 2.80 & 0.003 & 94.44 \\
0.8 & 2.67 & 1.86 & 0 & 95.47 \\
\hline
\end{tabular}



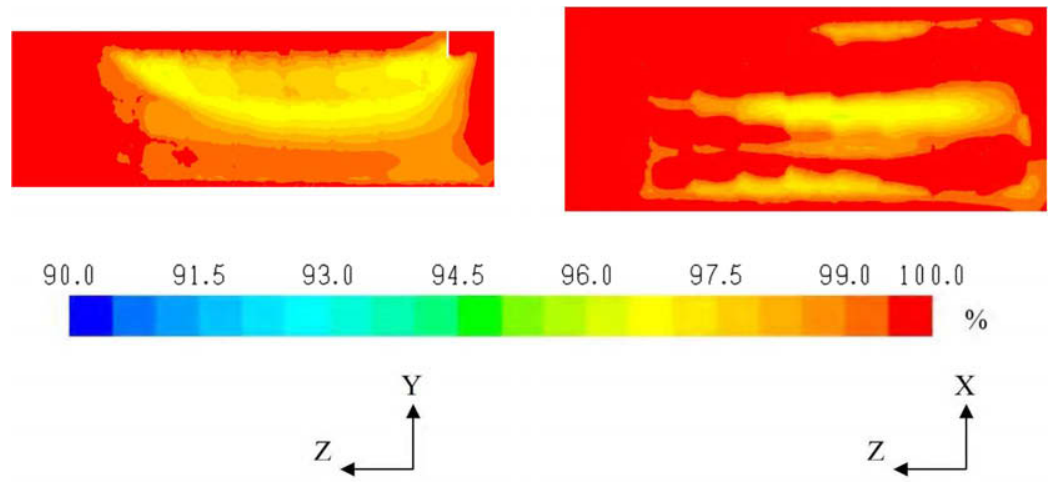

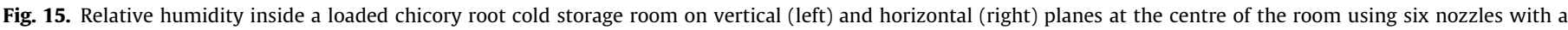
spraying time of $0.5 \mathrm{~min}$, for a deflector length of $0.8 \mathrm{~m}$.

With this new room design, the requirements for humidification could be different. For the different deflector lengths analysed, the calculated amount of the sprayed droplets that was deposited on the stack and room surfaces, deposited in the cooling unit and evaporated is given in Table 3 for a humidification time of $0.5 \mathrm{~min}$. The amount that was deposited on different surfaces was decreasing with an increase in deflector length. Elongating the deflector length increased the amount that was evaporated. A longer deflector therefore produced a higher $\mathrm{RH}$ (compare Fig. 10b with Fig. 15). It is obvious that longer deflectors will also improve the efficiency of the humidification system.

\subsection{Effect of stack height}

Finally, providing more free air space on top of the stack may further improve evaporation of water droplets. Decreasing the stack height decreased the amount of droplets deposited on the top of the stack. With 0.5 min of humidification, a deflector length of $0.2 \mathrm{~m}$ and six nozzles with a spraying rate of $5 \mathrm{~L} \mathrm{~h}^{-1}$ per nozzle, it was decreased from $3.10 \%$ to $1.31 \%$. However, the total amount deposited on the floor was increased slightly from $3.57 \%$ to $3.96 \%$. As a result of the decrease in stack height, there was an increase in the total amount of droplets that was evaporated (increase from $93.31 \%$ to $94.55 \%$ ).

\section{Conclusion}

We have shown that the efficiency of a cold storage humidification system depends on the cold store design (in particular the deflector length), stacking height, number of nozzles and duration of humidification. It was possible to minimize the amount of spray deposition on the stack, room surfaces and maximize the amount of droplets evaporated by elongating the air deflector. Reducing the stack height increased the amount of water evaporated and decreased the amount deposited on the stack, but the amount deposited on the floor of the room was increased.

The duration of humidification time was found to be the most important factor that controls the rate of evaporation and deposition. With an increase of the humidification time, there was an increase of the amount deposited and a decrease of the amount evaporated. Using the original six nozzles and an interval humidification of $0.5 \mathrm{~min}$ on and $2 \mathrm{~min}$ off cycle, it was possible to maintain the required room $\mathrm{RH}(95-100 \%)$ with a relatively low surface deposition of the sprayed droplets. Using two nozzles and an interval humidification of $1.5 \mathrm{~min}$ on and $2 \mathrm{~min}$ off, it was also possible to maintain the required room $\mathrm{RH}$ even with lower amount of surface deposition. Based on these results, the following combinations of room design and operating parameters could clearly give the best performance of the humidification system: deflector length of $0.8 \mathrm{~m}$, two nozzles with an interval humidification of $1.5 \mathrm{~min}$ on and 2 min off cycle and stack height of $3.4 \mathrm{~m}$. The result demonstrated the applicability of CFD models to identify closer to the optimum operating conditions of the system and room designs to produce maximum evaporation and minimum deposition of the sprayed water droplets.

\section{Acknowledgements}

The K.U.Leuven Interfaculty Council for Development Co-operation (IRO), the K.U.Leuven Research Council (Project OT-08023), the Fund for Scientific Research (project G.06.03.08) and the Institute for the Promotion of Innovation by Science and Technology in Flanders (project IWT-060720) are gratefully acknowledged for financial support. Pieter Verboven is Fellow of the Industrial Research Fund of the K.U.Leuven.

\section{References}

Al-Hakim, K., Wigley, G., Stapley, A.G.F., 2006. Phase doppler anemometry studies of spray freezing. Transanctions of IChemE, Part A, Chemical Engineering Research and Design 84 (A12), 1142-1151.

Anciaux, F., Nourricier, S., Frère, M., Feldheim, V., Dumont, E., Lybaert, P., 2006 Evaluation of underground energy storage performance in Belgium. In: The 10th International Conference on Thermal Energy Storage, New Jersey, USA

Anon, 1980. Produktgegevens groente en fruit, vol. 3, mededeling nr. 30, Sprenger instituut, Wageningen, The Netherlands.

Anon, 2006. FLUENT 6.3 User's Guide. Fluent, Inc., Lebanon, NH, USA.

Antohe, B.V., Lage, J.L., 1997. A general two-equation macroscopic turbulence model for incompressible flow in porous media. International Journal of Heat and Mass Transfer 40 (13), 3013-3024.

Chourasia, M.K., Goswami, T.K., 2007. CFD simulation of effects of operating parameters and product on heat transfer and moisture loss in the stack of bagged potatoes. Journal of Food Engineering 80 (3), 947-960.

De Proft, M., Krebsky, E., Leuridan, S., 2000. Influence of root water loss on chicory quality. Acta Horticulturae 517, 209-216.

Delele, M.A., Schenk, A., Tijskens, E., Ramon, H., Nicolaï, B.M., Verboven, P., 2009 Optimization of the humidification of cold stores by pressurized water atomizers based on a multiscale CFD model. Journal of Food Engineering 91, 228-239.

Embrechts, A.J.M., 1989. Effect of water loss in chicory root on forcing yield. Acta Horticulturae 258, 513-514.

Faxen, H., 1922. Der widerstand gegen die bewegung einer starren kugel in einer zahen flussigkeit, die zwischen zwei parallen ebenen wanden eingeschlossen ist. Annalen der Physik 68, 89-119.

Forchheimer, P., 1901. Wasserbewegung durch Boden. Zeitschrift des Vereines Deuts Ingenieure 45, 1736-1741.

Foster, A.M., Barrett, R., James, S.J., Swain, M.J., 2002. Measurement and prediction of air movement through doorways in refrigerated rooms. International Journal of Refrigeration 25, 1102-1109.

Haider, A., Levenspiel, O., 1989. Drag coefficient and terminal velocity of spherical and nonspherical particles. Powder technology 58, 63-70. 
Henriod, R.E., 2006. Postharvest characteristics of navel oranges following high humidity and low temperature storage and transport. Postharvest Biology and Technology 42, 57-64.

Hertog, M.L.A.T.M., Ben-Arie, R., Róth, E., Nicolaï, B.M., 2004. Humidity and temperature effects on invasive and non-invasive firmness measures. Postharvest Biology and Technology 33, 79-91.

Hindmarsh, J.P., Russell, A.B., Chen, X.D., 2003. Experimental and numerical analysis of the temperature transition of a suspended freezing water droplet. International Journal of Heat and Mass Transfer 46, 1199-1213.

Hoang, M.L., Verboven, P., De Baerdemaeker, J., Nicolaï, B.M., 2000. Analysis of air flow in a cold store by means of computational fluid dynamics. International Journal of Refrigeration 23, 127-140.

Hoang, M.L., Verboven, P., Baelmans, M., Nicolaï, B.M., 2003. A continuum model for airflow, heat and mass transfer in bulk of chicory roots. Transactions of the ASAE 46 (6), 1603-1611.

Hoang, M.L., Verboven, P., Baelmans, M., Nicolaï, B.M., 2004. Sensitivity of temperature and weight loss in the bulk of chicory roots with respect to process and product parameters. Journal of Food Engineering 62, 233243.

Li, A., Ahmadi, G., 1992. Dispersion and deposition of spherical particles from point sources in a turbulent channel flow. Aerosol Science and Technology 16, 209226.

Masuoka, T., Takatsu, Y., 1996. Turbulence model for flow through porous media. International Journal of Heat and Mass Transfer 39 (13), 2803-2809.

Moureh, J., Menia, N., Flick, D., 2002. Numerical and experimental study of airflow in a typical refrigerated truck configuration loaded with pallets. Computers and Electronics in Agriculture 34, 25-42.

Moureh, J., Flick, D., 2004. Airflow pattern and temperature distribution in a typical refrigeration truck configuration loaded with pallets. International Journal of Refrigeration 27, 464-474
Nahor, H.B., Hoang, M.L., Verboven, P., Baelmans, M., Nicolaï, B.M., 2005. CFD model of the airflow, heat and mass transfer in cooling stores. International Journal of Refrigeration 28, 368-380.

Nakayama, A., Kuwahara, F., 2005. Algebraic model for thermal dispersion heat flux within porous media. AIChE Journal 51 (10), 2859-2864.

Nakayama, A., Kuwahara, F., 1999. A macroscopic turbulence model for flow in a porous medium. Journal of Fluids Engineering-Transactions of the ASME 121, 427-433.

Neefs, V., Leuridan, S., Van Stallen, N., De Meulemeester, M., De Proft, M.P., 2000 Frost sensitiveness of chicory roots (Cichorium intybus L.). Scientia Horticulturae 86, 185-195.

Paull, R.E., 1999. Effect of temperature and relative humidity on fresh commodity quality. Postharvest Biology and Technology 15, 263-277.

Saffman, P.G., 1965. The lift on a small sphere in a slow shear flow. Journal Fluid Mechanics 22, 385-400.

Seynnaeve, M.C., Sarrazyn, R., Vanderschelden, C., Calus, A., 2000. Study on red discoloration of chicory heads. Acta Horticulturae 511, 89-98.

Sujau, M., Merts, I., Cleland, J., 2005. Relative humidity control in refrigerated facilities. Acta Horticulturae 687, 313-320.

Tassou, S.A., Xiang, W., 1998. Modelling the environment within a wet air-cooled vegetable store. Journal of Food Engineering 38, 169-187.

Tu, K., Nicolaï, B., De Baerdemaeker, J., 2000. Effect of relative humidity on Apple quality under simulated shelf temperature storage. Scientia Horticulturae 85 217-229.

van der Sman, R.G.M., 2008. Scale analysis and integral approximation applied to heat and mass transfer in packed beds. Journal of Food Engineering 85, 243251.

Verboven, P., Hoang, M.L., Baelmans, M., Nicolaï, B.M., 2004. Airflow through Beds of Apples and Chicory Roots. Biosystems Engineering 88 (1), 117-125.

Xu, Y., Burfoot, D., 1999. Simulating the bulk storage of food stuffs. Journal of Food Engineering 39, 23-29. 